\title{
Fabrication of Zirconia Abutment Crown and Clasp Under Existing Removable Partial Denture Using CAD/CAM Technology
}

\author{
Akinori Tasaka' \\ Takahiro Shimizu' \\ Takeshi Hirabayashi ${ }^{2}$ \\ Shuichiro Yamashita' \\ 'Department of Removable Partial \\ Prosthodontics, Tokyo Dental College, \\ Tokyo, Japan; ${ }^{2}$ Dental Laboratory of \\ Suidobashi Hospital, Tokyo Dental \\ College, Tokyo, Japan
}

\begin{abstract}
This clinical report describes a technique for fabricating a retrofit zirconia crown and clasp for an existing removable partial denture (RPD) using computer-aided design and computer-aided manufacturing (CAD/CAM). A 58-year-old patient developed acute pulpitis of a tooth, and the RPD clasp was broken on the tooth. A pre-preparation scan was captured using an intraoral scanner. The existing RPD was placed in the mouth, and scans of the postpreparation, antagonist arch, and interocclusal record were made. A zirconia crown was designed by superimposing the pre-preparation scan and the post-preparation scan of the abutment tooth. The design data were transferred to a 5-axis milling machine, and the crown was milled from zirconia. The crown was luted using resin cement. An intraoral scan of the crown with RPD was taken, and the RPD was removed to re-scan the proximal guide plane of the crown. The I-bar clasp was designed, and the casting pattern was built using a 3D printer. The pattern was used to cast the clasp. The clasp was set using autopolymerizing acrylic resin to the RPD. The main advantages of this efficient process are that patients can use their RPDs during fabrication of the crown of the abutment tooth. The limitations of using this technique include the cost of the intraoral scanner and the education for the dental clinicians and technicians. In this clinical report, CAD/CAM technology prevented human error, required no adjustment, and uninterrupted use of the RPD for fabricating a retrofit zirconia crown and clasp for an existing RPD.
\end{abstract}

Keywords: removable partial denture, denture repair, CAD/CAM, zirconia crown, I bar clasp

\section{Introduction}

Fabricating a crown to restore an abutment for an existing removable partial denture (RPD) is a complicated procedure. ${ }^{1}$ Numerous reports of indirect and direct techniques for new crown fabrication to fit an existing RPD have been published since $1960 .^{2}$ The main advantage of the direct technique is that the patients can wear their existing RPD during the crown fabrication process. However, increased clinical time is required to fit the inner surface of the RPD using wax or resin, because of the difficulty in manipulating the crown pattern directly in the oral environment. The indirect procedure uses a pickup impression of the RPD or an index of an abutment by which all information is transferred to a gypsum cast, and the contour and design of the restoration are completed in the dental laboratory. However, the disadvantage is that the existing denture must be sent to the dental laboratory. ${ }^{3}$ Recently, a procedure using computer-aided design and computer-aided manufacturing (CAD/CAM) has
Correspondence: Akinori Tasaka Department of Removable Partial Prosthodontics, Tokyo Dental College,

2-9-I 8 Kandamisakicho Chiyoda-ku,

Tokyo, I0I-006I, Japan

Tel +8I-3-6380-9167

Fax +8I-3-6380-9167

Email atasaka@tdc.ac.jp 
been introduced to obtain a crown with appropriate fit and contour in some clinical cases. ${ }^{3-11}$ Using CAD/CAM for this task reduces the number of steps for the process and, therefore, the potential for error. ${ }^{8}$ This procedure typically does not require the existing RPD to be sent to the dental laboratory, so patients have no trouble with daily life.

The most common approach for repairing a broken clasp on a RPD is embed it in the acrylic resin base using autopolymerizing acrylic resin. ${ }^{12}$ In the conventional method, the damaged clasp is removed, the groove for the clasp tang is added on the polished surface of the denture base, and make the impression using impression material. ${ }^{13}$ The impression must be made while the denture is placed in position and since it is not possible to take forms of the guide planes of all the abutment teeth, so the path of insertion of RPD is unclear. The application of CAD/CAM technology can take the intraoral scanning with and without dentures, and superimposing the two sets of data using software, thus solving the above problem.

The purpose of this clinical report was to describe a technique for fabricating a retrofit zirconia crown and clasp for an existing RPD using CAD/CAM technology.

\section{Case Report}

A 58-year-old man visited the Department of Prosthodontics of Suidoubashi Hospital at Tokyo Dental College complaining of tooth pain involving the mandibular left canine (tooth 33). He was wearing an RPD that had been fabricated 6 years previously. Although the clasp of the RPD on the tooth 33 abutment was broken, there was no loss of clinical stability, and the patient was satisfied with the prosthesis (Figure 1). On dental examination, dental caries of tooth 33 that extended into the pulp was found and diagnosed as acute pulpitis (Figure 2). Endodontic therapy was performed, and the damaged pulp was removed in a root canal. The tooth cavity was then cleaned and filled in. The anterior teeth containing the unprepared abutment tooth were captured by an intraoral scanner (Trios3; 3Shape, Copenhagen, Denmark) (Figure 3). The scanned data were sent to a dental laboratory for design and manufacture of the provisional restoration. Design software (Dental System; 3Shape) was used to copy the form data and the coordinate position of the abutment tooth and to trim the data at the gingival margin. Automatically filled data after the trim that was hollowed out to a 0.65 -mm thickness were used as the provisional restoration data (Figure 4). The data were sent to a 5-axis milling machine (DWX-51D; Roland, Shizuoka, Japan), and the provisional restoration was milled from a polymethyl methacrylate disc (Resin Disc A3; Yamahachi Dental Mfg. Co., Aichi, Japan). The tooth was prepared for the fiber post and core. Adequate clearance between the abutment teeth and the framework was established for placement under the existing RPD. Digital scans of the post-preparation, the antagonist arch, and the interocclusal record were made using an intraoral scanner. The provisional restoration was fitted to the abutment tooth using autopolymerizing acrylic resin (UNIFAST; GC, Tokyo, Japan). The

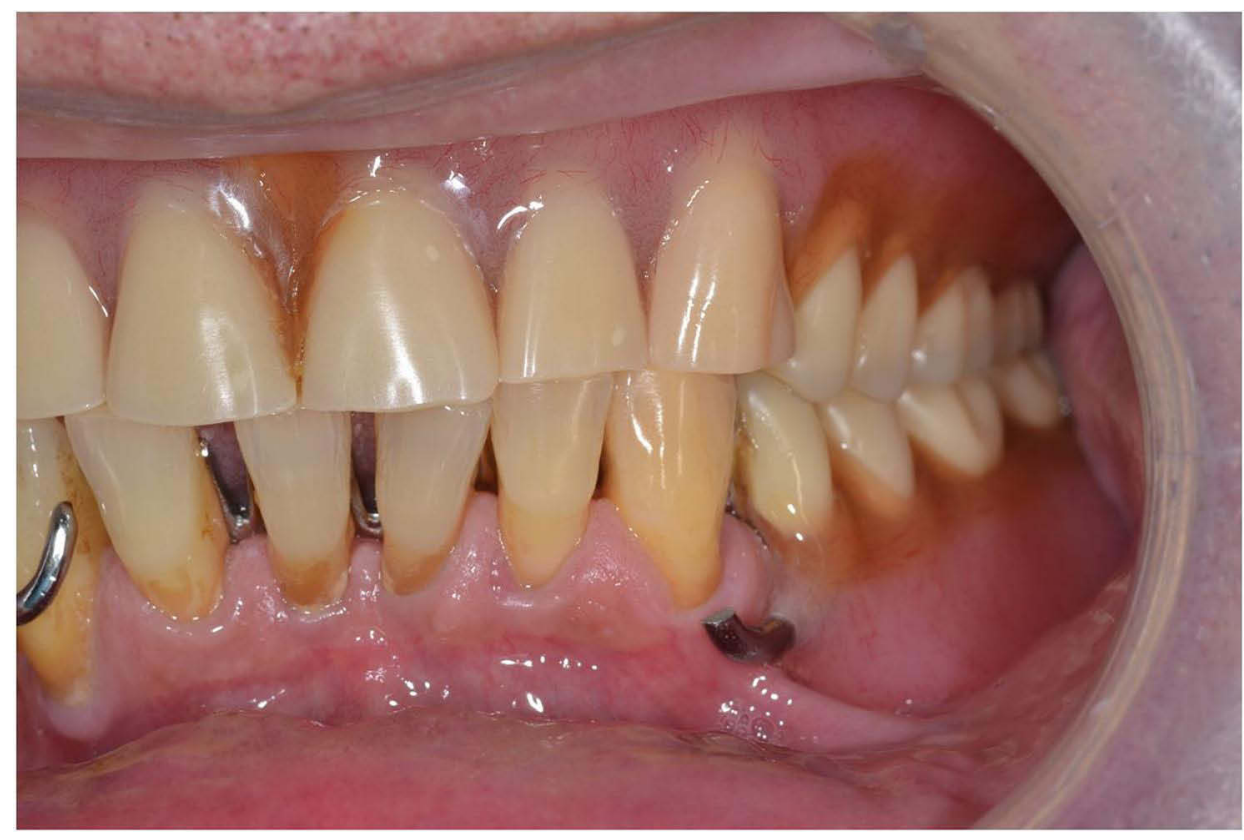

Figure I Intraoral photographs at initial examination. I-bar clasp on the canine is broken. 


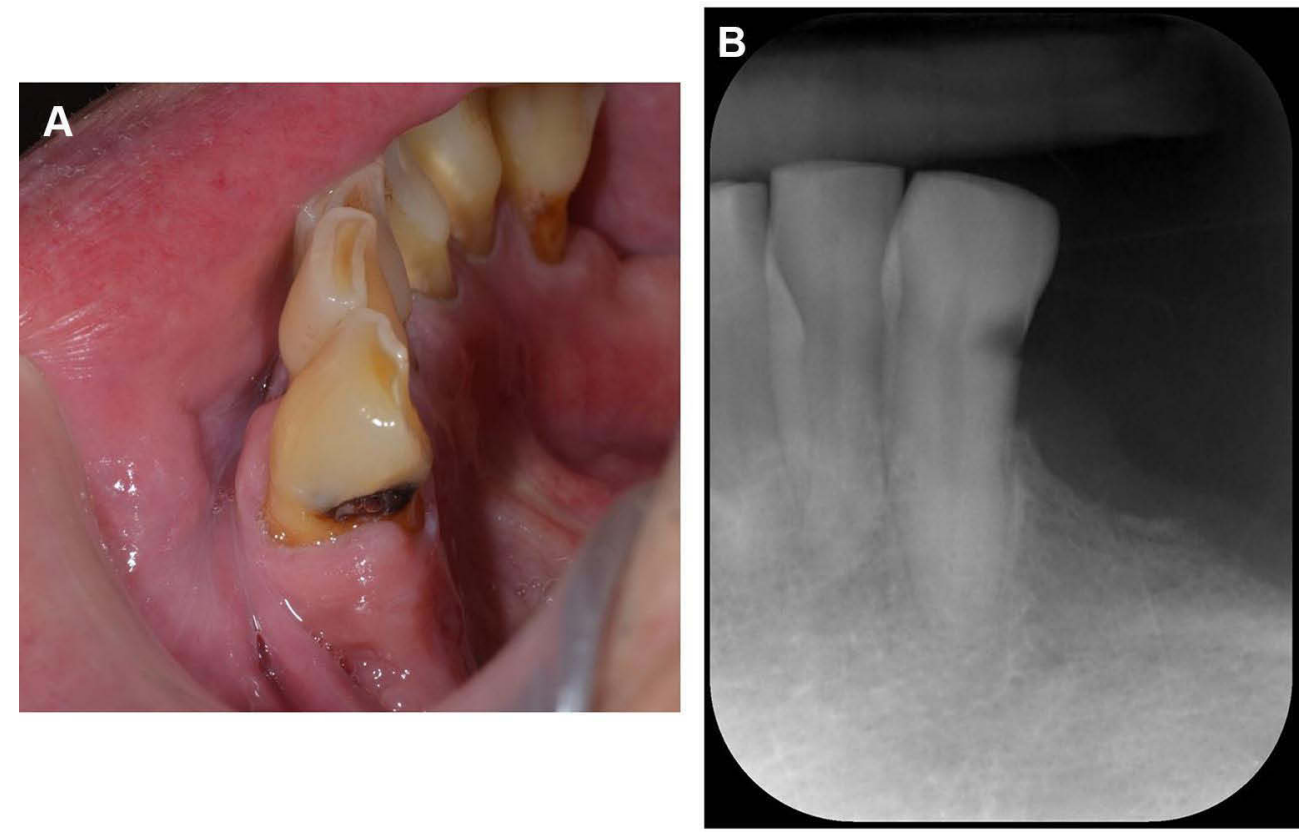

Figure 2 (A) Intraoral photographs and (B) X ray image obtained at initial examination. Caries of the mandibular left second canine.
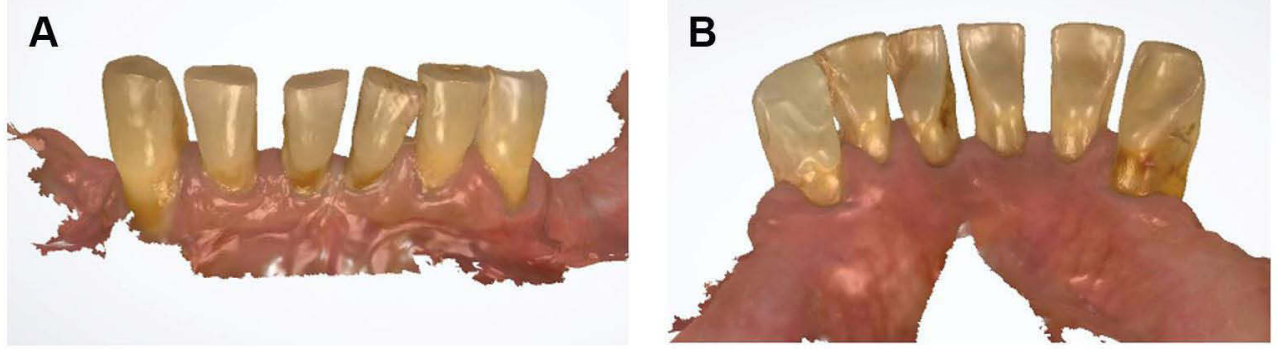

Figure 3 (A) Intraoral scan images after root canal treatment (frontal view). (B) Intraoral scan images after root canal treatment (lingual view). Intraoral scan of the mandibular left canine before preparation.

provisional restoration was luted to the prepared tooth, and the RPD was returned to the patient. A zirconia crown was designed by superimposing the pre-preparation scan and the post-preparation scan of the prepared abutment tooth (Figure 5). The crown contour was adjusted to $0.5-\mathrm{mm}$ undercut on the mesiolabial surface using a $2 \mathrm{D}$ cross-section and a distance measuring tool (Figure 6). The crown was milled from a zirconia disc (SHOFU DISK ZR Lucent Supra A3; Shofu, Kyoto, Japan) using a 5-axis milling machine. The completed crown was inspected intraorally to verify the occlusal contacts, marginal adaptation, and fit to the RPD framework. The crown was luted using resin cement (RelyX Adhesive Resin Cement; 3M ESPE, St. Paul, MN, USA). The damaged clasp was removed, and the surface of the denture base resin corresponding to the clasp tang of the new I-bar was eliminated. An intraoral scan of the crown with RPD was taken, and the RPD was removed to rescan the proximal guide plane of the abutment tooth (Figure 7). The proximal guide plane of the data without RPD was used to determine the path of insertion, and the I-bar was designed using the data with the RPD. The design data were sent to a 3D printer (Freeform PRO2; Asiga, Sydney, Australia), and the casting pattern was built. After printing, the pattern was rapidly invested, and cobalt-chromium alloy (Zeta-cast co; ODIC, Osaka, Japan) was used to cast the clasp (Figure 8). Resin matrix ${ }^{14}$ was designed using individual tray mode to properly position the I-bar on the abutment tooth. The design data were sent to the 5-axis milling machine, and the matrix was milled from a resin disc (M-PM Disk Clear; Shofu, Kyoto, Japan) (Figure 9). The clasp was set to the RPD using autopolymerizing acrylic resin. The patient reported satisfactory retention and aesthetics of the RPD after treatment completion (Figure 10). 


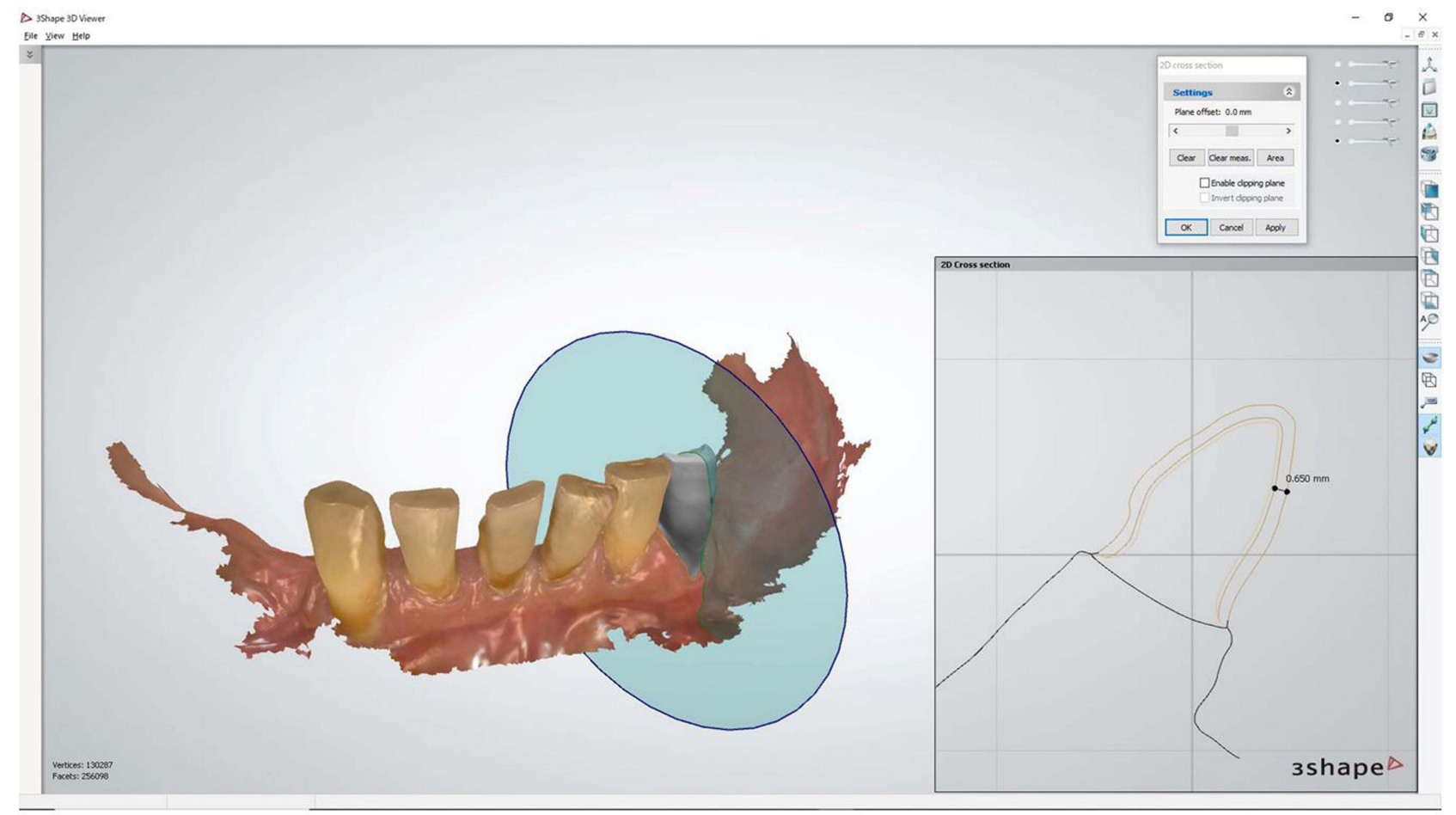

Figure 4 Design of the provisional restoration. The thickness was designed $0.65-\mathrm{mm}$.
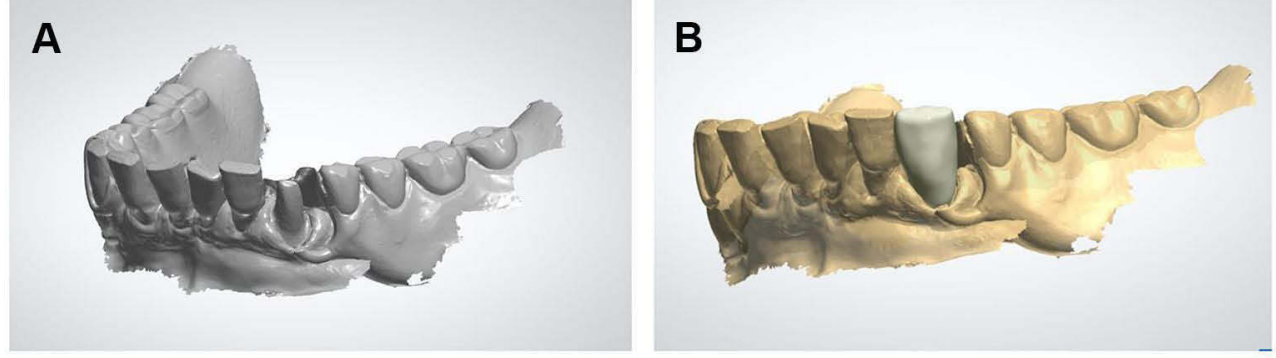

Figure 5 Preparation data and crown design. (A) The crown was designed by superimposing the pre-preparation scan and (B) the post-preparation scan of the prepared abutment tooth.

\section{Discussion}

The application of $\mathrm{CAD} / \mathrm{CAM}$ technology to fabricate a retrofit zirconia crown and to repair a clasp for an existing RPD was described. The main advantages of this efficient process are that patients can use their present RPD while the crown of the abutment tooth is fabricated. In addition, a crown contour was added to match the design of the I-bar clasp. The other advantage of using an intraoral scanner is that the positional relationship between an existing RPD and the oral cavity does not shift because pressure is not generated by the impression material. By reproducing the path of insertion of RPD, the patient could also set and remove the denture smoothly, and by setting the I bar tip, the required undercut and appropriate retentive force could be achieved, and no adjustment was needed after repair.

The conventional techniques of manufacturing crowns under the existing RPD have tried to combine the data after the preparation of the abutment tooth and the data of the inner surface of the clasp using materials such as polyvinyl siloxane and resin, ${ }^{1,5,6,9}$ or to combine the data before and after the preparation of the abutment tooth without the denture. ${ }^{3,4,8}$ The technique in this article improved the fit of the crown to the denture by combining data without the denture before and with the denture after the preparation of the abutment tooth. In addition, 


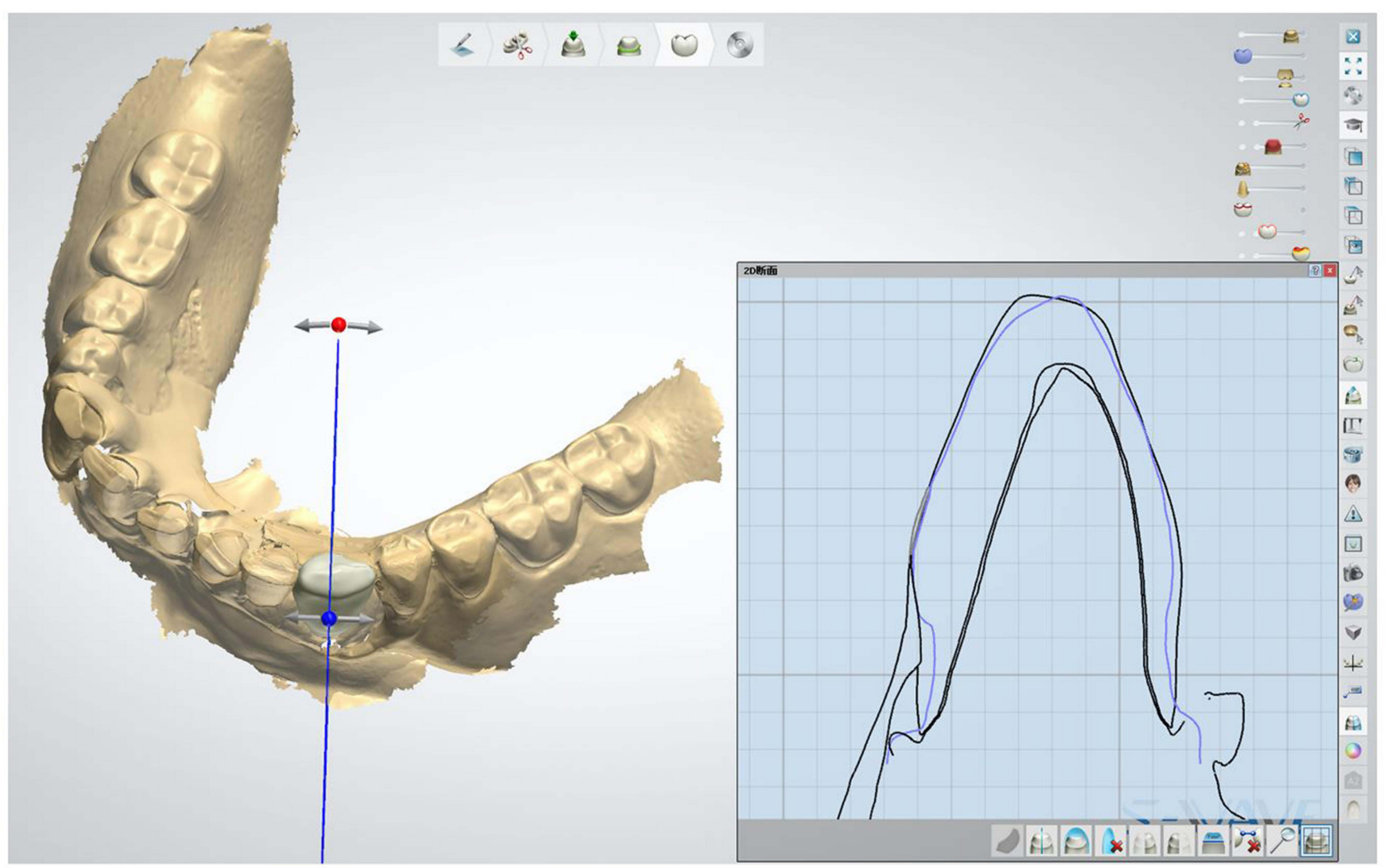

Figure 6 Adjustment of the crown contour. Blue line: Tooth outline of the pre-preparation scan. Black line: Design outline of the zirconia crown.
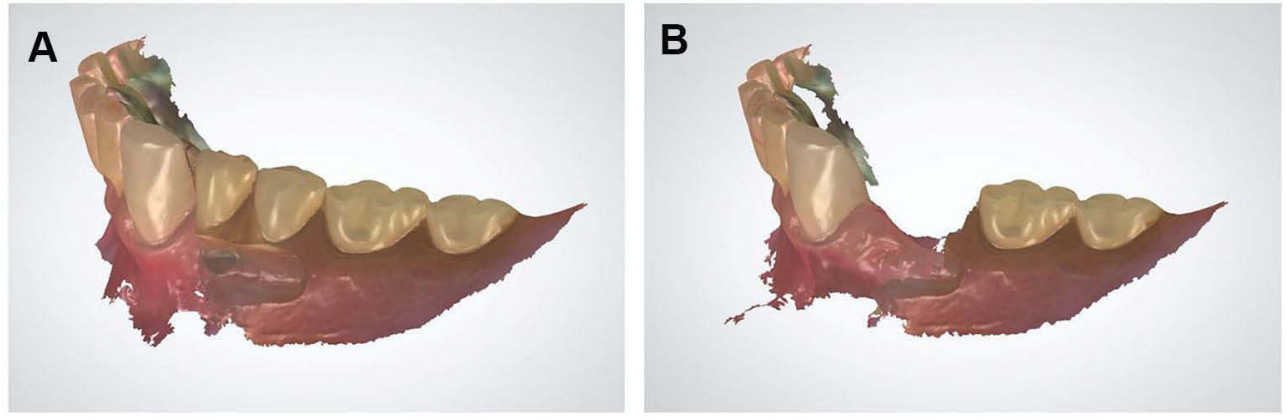

Figure 7 Intraoral scan images for fabricating clasp. (A) Intraoral scan of the mandible with the RPD. (B) Rescan proximal guide plane of the abutment tooth without the RPD.

although previous reports have described the fabrication of provisional restorations by the direct or indirect method using a vacuum form, ${ }^{1,3,6}$ in this paper, provisional restorations that fit the denture in use could be fabricated by processing the data of the abutment teeth before the preparation using CAD software.

In this case report, the crown and clasp were fabricated separately. However, if the clasp is designed on the data of the digital wax-up of the crown using an intraoral scanner and $\mathrm{CAD} / \mathrm{CAM}$, it could be possible to further improve the efficiency of treatment. In addition, the fabrication of clasps by metal additive manufacturing as selective laser melting can improve the efficiency of dental laboratory and save materials. The clasp fabrication method in this technical paper is currently available in many dental laboratories; however, dental laboratories with selective laser melting 


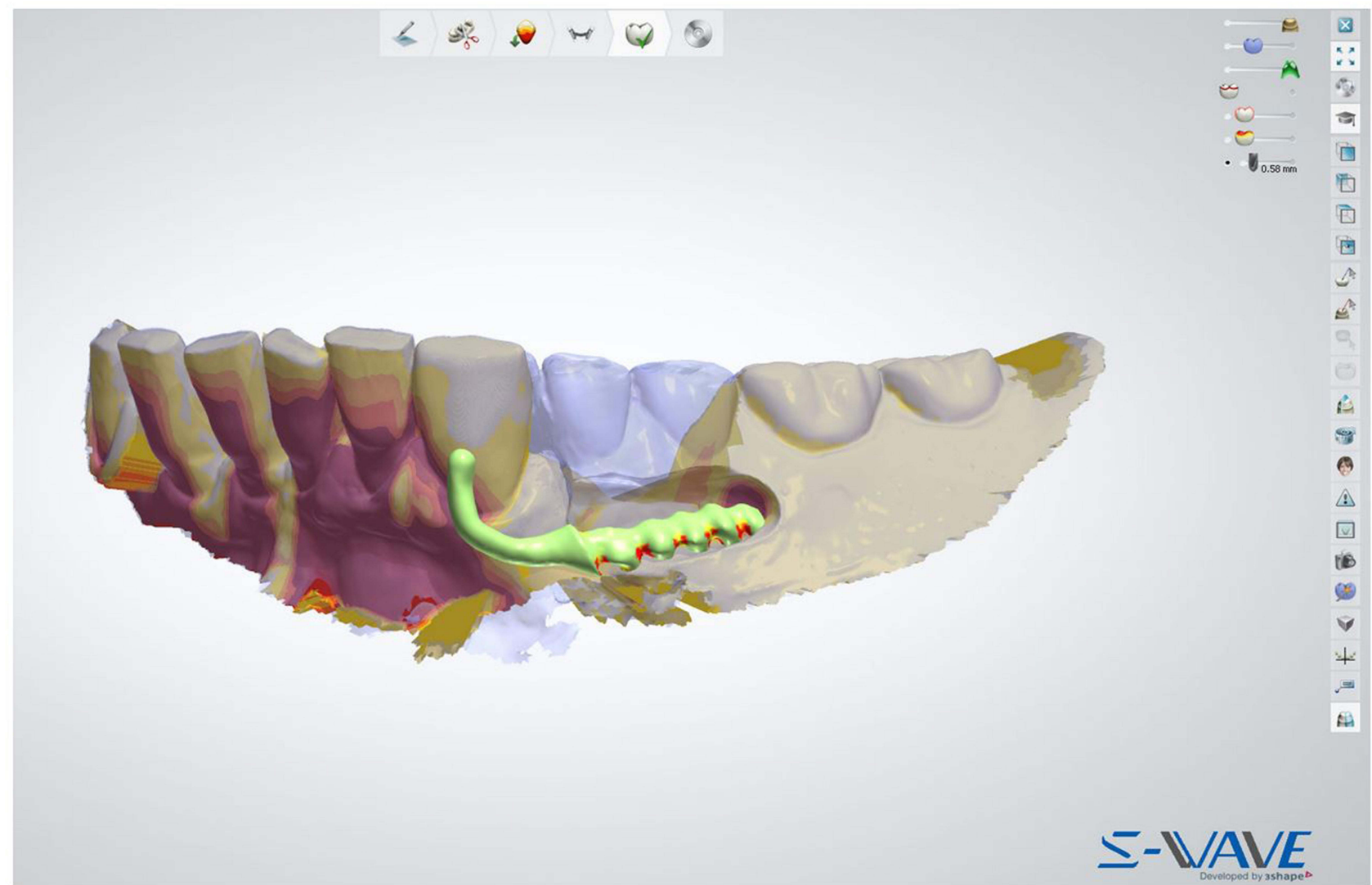

Figure 8 Design of I-bar clasp. CAD software view of the scan with the removed RPD (gray) and merged with the RPD worn (blue). Between the yellow and the orange on the clasp tip is undercut of $0.5 \mathrm{~mm}$.

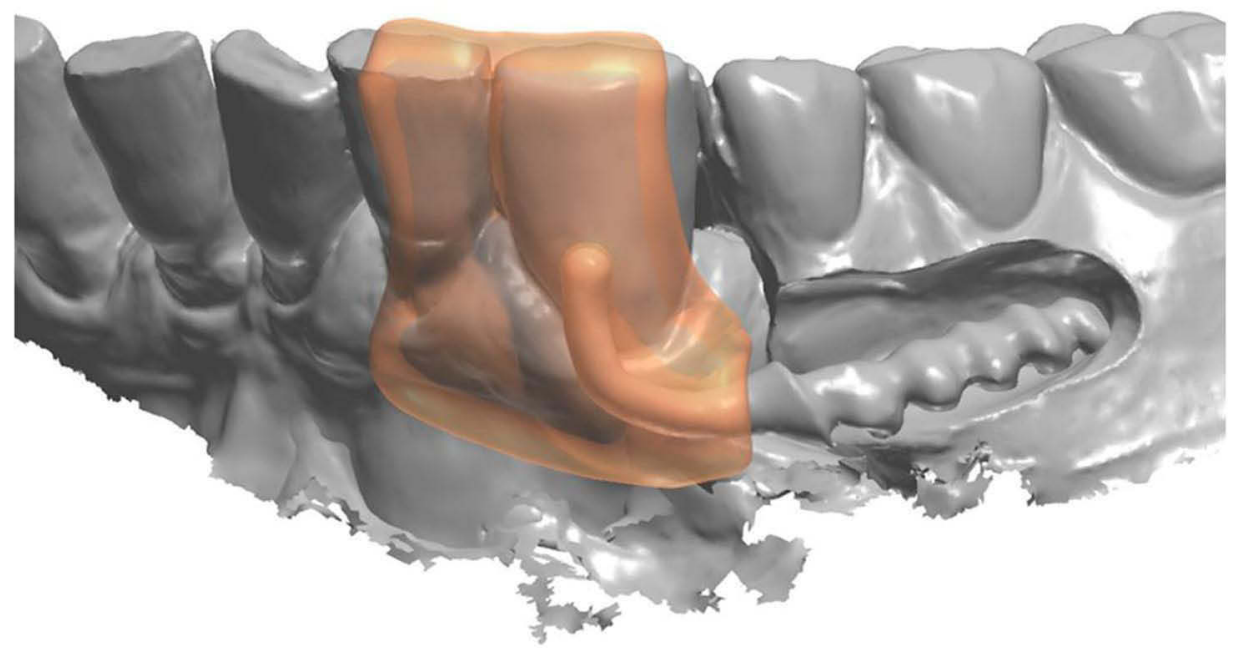

Figure 9 CAD software view of the resin matrix. Resin matrix was designed using individual tray mode of CAD software.

technology are not yet common. The limitations of using this technique include the cost of the intraoral scanner and the education for the dental clinicians and dental technicians.

\section{Conclusion}

In this clinical report, $\mathrm{CAD} / \mathrm{CAM}$ technology prevented human error, required no adjustment, and uninterrupted 

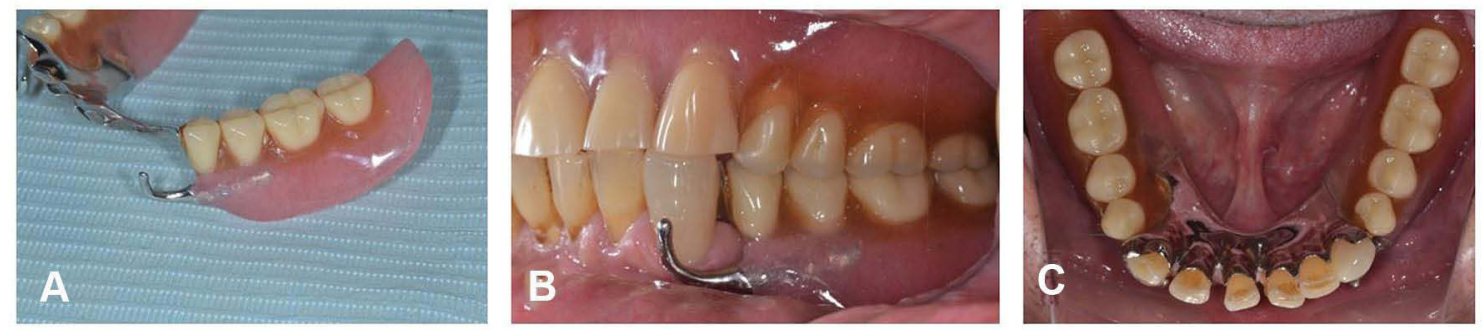

Figure 10 (A) Denture photographs and (B and $\mathbf{C}$ ) intraoral after treatment. Retrofitted zirconia crown and I-bar clasp under the existing RPD.

use of the RPD for fabricating a retrofit zirconia crown and clasp for an existing RPD.

\section{Statement of Informed Consent and Institutional Approval}

Written informed consent was obtained from the patient for publication of this case report and accompanying images. No institutional approval was required to publish the case details.

\section{Funding}

This clinical report did not receive any specific grant from funding agencies in the public, commercial, or not-forprofit sectors.

\section{Disclosure}

The authors declare no conflicts of interest.

\section{References}

1. Marchack BW, Chen LB, Marchack CB, Futatsuki Y. Fabrication of an all-ceramic abutment crown under an existing removable partial denture using CAD/CAM technology. J Prosthet Dent. 2007;98 (6):478-482. doi:10.1016/S0022-3913(07)60148-6

2. Tran CD, Sherraden DR, Curtis TA. A review of techniques of crown fabrication for existing removable partial dentures. J Prosthet Dent. 1986;55(6):671-673. doi:10.1016/0022-3913(86)90439-7

3. Yoon TH, Chang WG. The fabrication of a CAD/CAM ceramic crown to fit an existing partial removable dental prosthesis: a clinical report. $J$ Prosthet Dent. 2012;108(3):143-146. doi:10.1016/S0022-3913(12)60137-1

4. Gouveia DNM, Razzoog ME, Alfaro MF. A fully digital approach to fabricating a CAD-CAM ceramic crown to fit an existing removable partial denture. J Prosthet Dent. 2019;121(4):571-575. doi:10.1016/j. prosdent.2018.09.009
5. Lee JH. Completely digital approach to fabricating a crown under an existing partial removable dental prosthesis by using an intraoral digital scanner in a single appointment. $J$ Prosthet Dent. 2016;115 (6):668-671. doi:10.1016/j.prosdent.2015.11.021

6. El Kerdani T, Roushdy S. The use of CAD/CAM technology for fabricating cast gold survey crowns under existing partial removable dental prosthesis. A clinical report. J Prosthodont. 2017;26 (4):321-326. doi:10.1111/jopr.12525

7. Su FY, Tsai JC, Morton D, Lin WS. Use of an open-source CAD software program and additive manufacturing technology to design and fabricate a definitive cast for retrofitting a crown to an existing removable partial denture. J Prosthet Dent. 2019;122(4):351-354. doi:10.1016/j.prosdent.2019.02.017

8. Smith CS, Grandin H, Low K. A predictable all-digital workflow to retrofit a crown to an existing removable prosthesis. $J$ Prosthet Dent. 2019;121(6):876-878. doi:10.1016/j.prosdent.2018.08.014

9. Lee JH. Fabricating a crown under an existing removable partial denture with impression scanning and CAD-CAM technology. J Prosthet Dent. 2020;124(2):148-152. doi:10.1016/j.prosdent.2019.06.016

10. Bae MS, Oh WS, Park YH, Lee JJ. Digital workflow for retrofitting a surveyed crown using a removable partial denture as an antagonist. J Prosthodont. 2020;29(6):542-545. doi:10.1111/jopr.13187

11. Hosney S, Carranza MG, Geminiani A, Ercoli C, Papaspyridakos P, Chochlidakis K. A combined analog and digital workflow for retrofitting a monolithic ceramic crown to an existing removable partial denture. J Prosthet Dent. 2021;125(4):585-587. doi:10.1016/j. prosdent.2020.03.024

12. Lu DP. Chairside replacement of fractured clasp for removable partial denture. J Prosthet Dent. 1983;49(2):282-285. doi:10.1016/00223913(83)90517-6

13. Livaditis GJ. Repair with a surveyed cast clasp while patient retains the partial denture. $J$ Prosthet Dent. 1997;77(6):624-629. doi:10.1016/S0022-3913(97)70106-9

14. Sato Y, Tsuga K, Hosokawa R. Accurate procedure for transferring a cast replacement clasp arm to a removable partial denture. $J$ Prosthet Dent. 1999;82(5):619-622. doi:10.1016/S0022-3913(99)70065-X
Clinical, Cosmetic and Investigational Dentistry

\section{Publish your work in this journal}

Clinical, Cosmetic and Investigational Dentistry is an international, peer-reviewed, open access, online journal focusing on the latest clinical and experimental research in dentistry with specific emphasis on cosmetic interventions. Innovative developments in dental materials, techniques and devices that improve outcomes and patient satisfaction and preference will be highlighted. The manuscript management system is completely online and includes a very quick and fair peer-review system, which is all easy to use. Visit

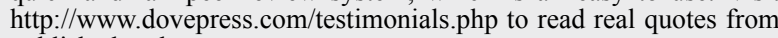
published authors. 